Supplement of SOIL, 6, 435-451, 2020

https://doi.org/10.5194/soil-6-435-2020-supplement

(C) Author(s) 2020. This work is distributed under

the Creative Commons Attribution 4.0 License.

(c) (1)

Supplement of

\title{
Land-use perturbations in ley grassland decouple the degradation of ancient soil organic matter from the storage of newly derived carbon inputs
}

Marco Panettieri et al.

Correspondence to: Abad Chabbi (abad.chabbi@inrae.fr)

The copyright of individual parts of the supplement might differ from the CC BY 4.0 License. 
Figure S1.
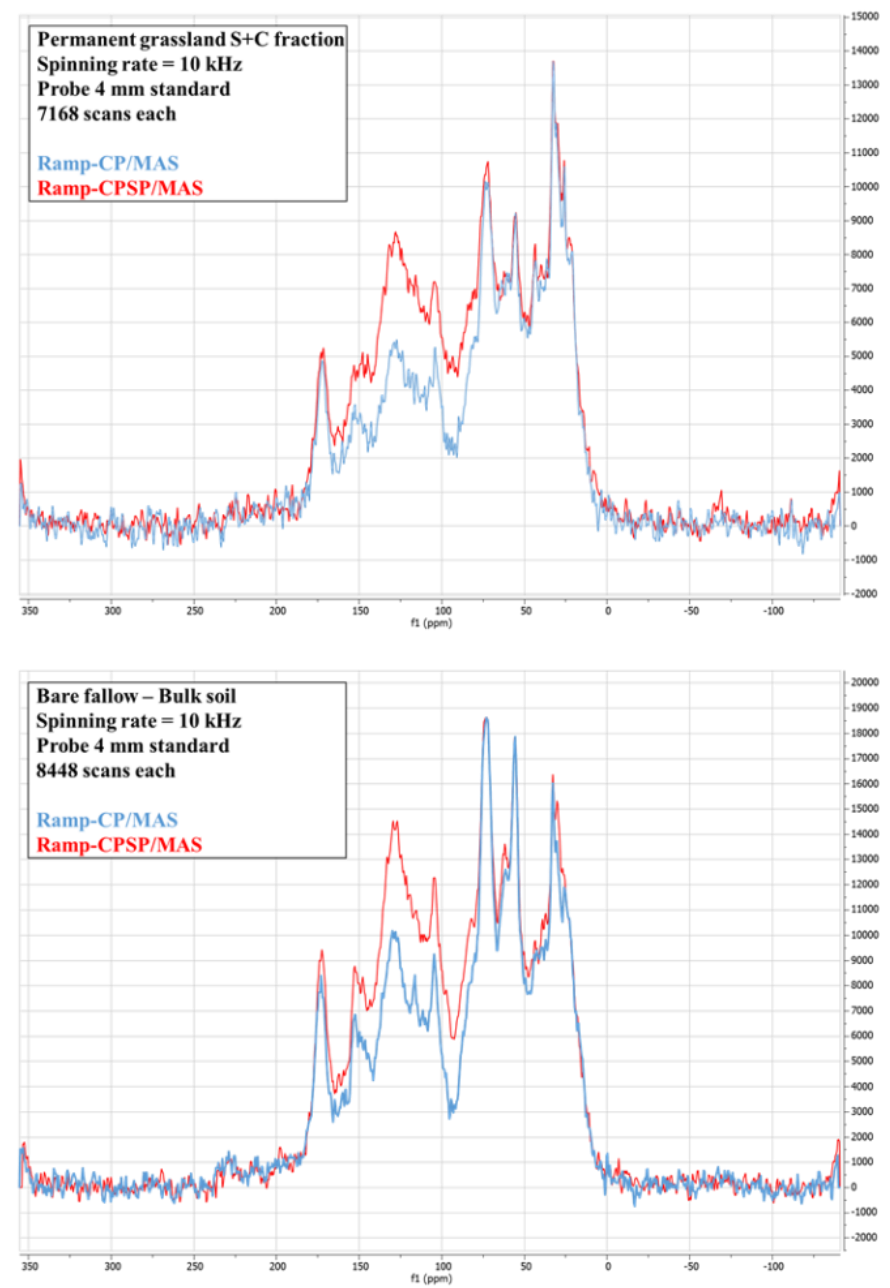